Rev Inv Vet Perú 2005; 16 (2): 158-162

\title{
CUANTIFICACIÓN DE Brucella sp. EN BOVINOS DE LA PROVINCIA DE CANTA, LIMA
}

\section{Carmen Huguet T. ${ }^{1}$, Alfredo Delgado C. ${ }^{2}$, Sonia Calle E. ${ }^{3}$ y Armando González Z. ${ }^{4}$}

\section{Abstract}

The objective of this study was to determine the presence of Brucella sp. in cattle of the province of Canta, Lima, through the detection of antibodies in blood using the Rose Bengal test and then, the complement fixation test to confirm positive sera. A total of 486 serum samples were analysed and only one from the district of Santa Rosa de Quives was found positive. This indicated that the prevalence was $0.21 \%(1 / 486)$ with a confidence interval of 0.09 till $0.60 \%$. The results showed that the presence of Brucella sp. in the province of Canta was very low, which may allow the implementation of a program for Brucella eradication.

Key words: bovine brucellosis, Rose Bengal test, complement fixation test, antibody

\section{RESUMEN}

El objetivo del presente estudio fue determinar la presencia de Brucella sp. en el ganado bovino de la provincia de Canta, Lima, mediante la detección de anticuerpos en suero a través de la prueba inicial de Rosa de Bengala y la de Fijación de Complemento como prueba confirmatoria. Se procesaron 486 muestras de suero en toda la provincia encontrándose un animal positivo a Brucella sp. en el distrito de Santa Rosa de Quives, lo que significó una prevalencia de $0.21 \%$ con intervalo de confianza mínimo de 0.09 y máximo de $0.60 \%$. Los resultados indican una baja prevalencia, lo que permitiría implementar un programa de erradicación de brucelosis bovina en la provincia de Canta.

Palabras clave: brucelosis bovina, Rosa de Bengala, fijación de complemento, anticuerpo

\footnotetext{
${ }^{1}$ Práctica privada

${ }^{2}$ Clínica de Animales Mayores, FMV-UNMSM. E-mail: aldelgado@viabcp.com

${ }^{3}$ Laboratorio de Microbiología y Parasitología Veterinaria, FMV-UNMSM

${ }^{4}$ Laboratorio de Medicina Veterinaria Preventiva, FMV-UNMSM
} 
INTI

La brucelosis bovina es una enfermedad infecciosa, zoonótica, de distribución mundial y de gran importancia económica en lo que respecta a producción de carne y leche (Acha y Szyfres, 2003; Aréstegui et al., 2001).

En el género Brucella se reconocen actualmente seis especies: $B$. melitensis, $B$. abortus, $B$. suis, $B$. neotomae, $B$. ovis y $B$. canis. Recientemente se ha identificado la $B$. cetaceae y B. pinnipediae en mamíferos marinos, incluyendo a cetáceos de las costas peruanas (Van Bressem et al., 2001). El patógeno principal en el ganado bovino es B. abortus, siendo el biovar 1 de carácter universal y el predominante de los siete biovares que ocurren en el mundo. No obstante, los bovinos también pueden infectarse con B. suis y B. melitensis cuando comparten el pastoreo o las instalaciones con cerdos, cabras u ovejas infectadas. La infección en bovinos por estas especies de brucela suele ser menos frecuente que por $B$. abortus, pero acarrea un grave peligro para la salud pública, ya que las vacas pueden excretar las bacterias por la leche (Blasco, 2001)

La vía de infección en animales es principalmente por vía oral, a través de la ingestión de pastos, forrajes o agua contaminada; pero además, cuando lamen las membranas fetales, fetos, terneros recién nacidos y órganos genitales de otras vacas. La propagación en el organismo tiene lugar después de la fagocitosis de la bacteria por los macrófagos, localizándose con preferencia en el tejido reticuloendotelial y en el tracto genital como los testículos y glándulas accesorias, en el útero gestante, así como en los ganglios linfáticos accesorios, especialmente los supramamarios. En animales gestantes, la $B$. abortus tiene predilección por el útero grávido, quizás debido a la presencia del eritritol, que se encuentra presente en altas concentraciones tanto en la placenta como en las membranas fetales. La B. abortus invade la placenta y produce una severa placentitis, ocasionando el aborto, que ocurre mayormente entre el sétimo y octavo mes de gestación. Una consecuencia común del aborto es la retención de la placenta con la subsiguiente metritis e infertilidad (Radostits et al., 2002).

El Perú cuenta con un programa sanitario de control y erradicación de brucelosis bovina desarrollado por el Servicio Nacional de Sanidad Agraria (SENASA) donde utilizan la prueba de anillo de leche como prueba inicial. Los animales positivos a esta prueba son sometidos a una segunda prueba selectiva, mediante la prueba de Rosa de Bengala, y los sueros que resultan positivos son confirmados con la prueba de Fijación de Complemento (SENASA, 2003) .

La brucelosis bovina está muy difundida en el país, especialmente en las cuencas lecheras de Arequipa, Trujillo, Cajamarca y Lima, en donde el sistema de explotación es estabulado o semiestabulado. Los últimos reportes realizados por el SENASA en el año 2000 denotan una prevalencia de $0.06 \%$ en los departamentos de Lima, Arequipa y Cajamarca; sin embargo, no se especifica la situación de los animales de la provincia de Canta (SENASA, 2003). Por ello el presente estudio se diseñó para determinar la presencia de brucelosis bovina en el ganado bovino de la provincia de Canta, departamento de Lima.

\section{Materiales y Métodos}

\section{Lugar de estudio y animales}

La provincia de Canta tiene una extensión territorial de $1,646.5 \mathrm{~km}^{2}$, comprende 7 distritos y 22 comunidades campesinas, y presenta altitudes entre los 550 a 4,450 msnm, con una temperatura promedio anual entre los 5 y $18^{\circ} \mathrm{C}$ y una precipitación pluvial anual de 465 a 1,976 mm (Vegas, 2003). 
Cuadro 1. Población bovina y tamaño muestral en los distritos de la provincia de Canta, departamento de Lima para la cuantificación de Brucella sp. (2003)

\begin{tabular}{lccccc}
\hline Distritos & $\begin{array}{c}\text { Población } \\
\text { bovina }^{1}\end{array}$ & $\begin{array}{c}\text { Unidades } \\
\text { agropecuarias }\end{array}$ & $\begin{array}{c}\text { Muestras } \\
\text { estimadas }\end{array}$ & $\begin{array}{c}\text { Muestras } \\
\text { trabajadas }\end{array}$ & $\begin{array}{c}\text { Unidades } \\
\text { agropecuarias }\end{array}$ \\
\hline Canta & 2,630 & 312 & 91 & 102 & 37 \\
Huamantanga & 3,271 & 312 & 113 & 122 & 24 \\
Huaros & 2,256 & 218 & 78 & 80 & 16 \\
Lachaqui & 2,100 & 223 & 72 & 73 & 10 \\
San Buenaventura & 1,122 & 94 & 39 & 40 & 9 \\
Arahuay & 986 & 97 & 34 & 34 & 8 \\
Santa Rosa de Quives & 903 & 91 & 31 & 35 & 7 \\
\hline \multicolumn{1}{c}{ Total } & 13,268 & 1347 & 458 & 486 & 111 \\
\hline
\end{tabular}

${ }^{1}$ Fuente: INEI, 1994

El tipo de ganado bovino predominante es criollo cruzado con Holstein. Los animales muestreados fueron vacas con edades entre los 2.5 a 4 años. Estos animales estuvieron únicamente vacunados contra el carbunclo sintomático. El tamaño muestral fue obtenido mediante el método de prevalencia límite del $1 \%$ con un nivel de confianza del $99 \%$, dando como resultado 458 animales. Este número se distribuyó proporcionalmente en cada distrito de la provincia de Canta, obteniéndose finalmente 486 animales (Cuadro 1).

\section{Muestras y métodos de diagnóstico}

Las muestras de sangre se obtuvieron entre octubre y diciembre del 2000 por venopunción de la coxígea o la yugular. El suero fue trasvasado en viales de $5 \mathrm{ml}$ y conservados en congelación a $-20{ }^{\circ} \mathrm{C}$ hasta su procesamiento.

La presencia de la Brucella sp. se determinó mediante la prueba de Rosa de Bengala como prueba inicial, y las muestras que resultaron positivas se analizaron con la prue- ba confirmatoria de Fijación de Complemento. En el análisis estadístico se utilizó la simulación Beta para obtener la prevalencia promedio y el intervalo de confianza.

\section{Resultados}

Se detectaron 2 sueros positivos a Rosa de Bengala de los 486 sueros analizados procedentes de los siete distritos que representa la provincia de Canta. De éstos, un animal dio positivo a la prueba de Fijación de Complemento. El animal pertenecía al distrito de Santa Rosa de Quives.

Según el análisis de simulación beta, el valor de prevalencia promedio de los animales muestreados fue de $0.21 \%\left(2.1 \times 10^{-1}\right)$, con un intervalo de confianza de 0.09 a $0.60 \%$.

\section{Discusión}

La prevalencia estimada $(0.21 \%)$ concuerda con resultados obtenidos en cuencas 
lecheras como el valle del Mantaro, cuya prevalencia fue de $0.28 \%$ usando la prueba de ELISA indirecta y de $0.83 \%$ con la prueba de Rosa de Bengala (Cruz, 1996). En la selva alta se ha reportado una prevalencia de 0.53\% (Cordero y Huanca, 1999).

El animal positivo demuestra la presencia de Brucella sp. en el ganado bovino de Canta, pudiendo ser B. abortus, B. melitensis o $B$. suis. Es posible, no obstante, que se deba a una infección por $B$. melitensis, debido a las características de explotación mixta (vacas y cabras) en Santa Rosa de Quives. Además, se tiene historia de $B$. melitensis en la población caprina de la zona (Vargas, 1999).

Es importante remarcar que el programa de erradicación de brucelosis bovina podría verse obstaculizado por infecciones debidas a $B$. melitensis. Los bovinos son susceptibles a infectarse con B. melitensis, de allí que se puede observar brotes de brucelosis en vacas, especialmente en poblaciones no vacunadas (Blasco, 2001).

El animal que dio positivo a la prueba de Rosa de Bengala y negativo a la prueba de Fijación de Complemento fue del distrito de Arahuay. La prueba de Rosa de Bengala puede dar resultados falsos positivos debido a la presencia de anticuerpos residuales por vacunación con $B$. abortus Cepa 19 y por reacciones cruzadas con otras bacterias Gram negativas que comparten un lipopolisacárido superficial similar al que presenta la Brucella. Dentro de estas bacterias se puede citar a $E$. coli O:116 y O:157, Francisella tularensis, Salmonella serotipos Kauffman-White del grupo N, Pseudomona maltophilia y Yersinia enterocolitica serotipo O:9 (Krieg y Holt, 1984).

La ausencia de animales positivos podría deberse a la geografía de la región y a la falta de vías de comunicación que limitan el ingreso de nuevos animales. Considerando la baja prevalencia de brucelosis, Canta debería tener un programa de erradicación me- diante pruebas serológicas de diagnóstico y sacrificio de animales positivos (Acha y Szyfres, 2003). Sin embargo, su implementación podría ser difícil debido a la natural resistencia de parte de los ganaderos a la eliminación de sus animales positivos, ya que muchas de las ganaderías son de subsistencia o para autoabastecimiento. Otro aspecto a considerar es el continuo movimiento de animales dentro de la provincia, donde los animales jóvenes y aquellos que se encuentren en seca son llevados a las alturas.

\section{Limeratura Citada}

1. Acha, P.; B. Szyfres. 2003. Zoonosis y enfermedades transmisibles comunes al hombre y en los animales. $3^{\mathrm{a}}$ ed. p 2853. Pub. Científica y Técnica. Organización Panamericana de Salud. Washington, USA.

2. Aréstegui, M; C. Gualtieri; J. Domínguez; G. Scharovsky. 2001. El género Brucella y su interacción con el sistema mononuclear fagocítico. Vet. Mex. 32: 131-139.

3. Blasco, J. 2001. Brucelosis animal: $\mathrm{La}$ enfermedad y medidas para su control y erradicación. Disponible en: http:// www.jcyl.es/jcyl-client/jcyl/ images?idMmedia=26459)

4. Cordero, A.; W. Huanca. 1999. Incidencia de Brucella abortus en ganado bovino cruzado en la zona de Pucallpa. Disponible en: http://tumi.lamolina.edu. pe/resumen/anales/1999 105.pdf

5. Cruz, J. 1996. Prevalencia de la brucelosis bovina en la cuenca lechera del valle del Mantaro. Tesis de Médico Veterinario. Facultad de Medicina Veterinaria, Univ. Nacional Mayor de San Marcos. Lima. 28 p.

6. INEI. 1994. III Censo Nacional Agropecuario (III CENAGRO). Disponible en: http://www.inei.gob.pe

7. Krieg, N.; J. Holt. 1984. Bergey's manual of systematic bacteriology. p 377388. Ed. Williams y Wilkins. USA. 
8. Radostits, O.; C. Gay; D. Blood; K. Hinchcliff. 2002. Medicina veterinaria. Tratado de las enfermedades del ganado bovino, ovino, porcino, caprino y equino. p 1025-1053. Ed. McGraw-Hill Interoamericana. España.

9. SENASA. 2003. Programa de control y erradicación de tuberculosis y brucelosis bovina. Disponible en: http:// www.senasa.gob.pe

10. Van Bressem, M.; K. Van Waerebeek; J. Raja; J. Godfroid; S. Brew; A. MacMillan. 2001. Serological evidence of Brucella species infection in ondontocetes from the South Pacific and the Mediterranean. Vet. Rec. 148: 657661.

11. Vargas, I. 1999. Prevalencia de Brucella melitensis en el valle de Chillón, Provincia de Canta, Departamento de Lima. Tesis de Médico Veterinario. Facultad de Medicina Veterinaria, Univ. Nacional Mayor de San Marcos. Lima. $37 \mathrm{p}$.

12. Vegas, J. 2003. A propósito del desarrollo del capitalismo en las comunidades campesinas de Canta: alcances y límites. Rev. Antropología, UNMSM 1: 87-92. 